\title{
Do the Locally Advanced Rectal Cancer Patients Enjoy Long-term Survival Benefit From the Radiation-based Neoadjuvant Treatments in the Total Mesorectal Excision Era: a Population-based Analysis
}

Lei Wang

Fujian Medical University

Xiaohong Zhong

Fujian Medical University

Huaqin Lin

Fujian Medical University

Xueqing Zhang

Fujian Provincial Cancer Hospital

Lingdong Shao

Fujian Provincial Cancer Hospital

Junxin Wu ( $\sim$ junxinwufj@aliyun.com )

Fujian Provincial Cancer Hospital https://orcid.org/0000-0003-1047-2338

\section{Research Article}

Keywords: Locally advanced rectal cancer, Total mesorectal excision, Radiation, Neoadjuvant treatment, Overall survival

Posted Date: March 17th, 2021

DOI: https://doi.org/10.21203/rs.3.rs-302960/v1

License: (c) (i) This work is licensed under a Creative Commons Attribution 4.0 International License.

Read Full License 


\section{Abstract}

Background: Radiation-based neoadjuvant therapy followed by radical surgery is the standard treatment for locally advanced rectal cancer (LARC), but things might have changed with the advent of total mesorectal excision (TME). This study re-evaluated the clinical efficacy of preoperative radiotherapy for LARC patients in the TME era by population-based analysis to identify any long-term survival benefits.

Methods: LARC patients receiving preoperative radiotherapy or not followed by surgery between 2011 and 2015 were extracted from the Surveillance, Epidemiology, and End Results (SEER) database. Overall survival (OS) was analyzed by Kaplan-Meier curves, and potential candidates for preoperative radiotherapy were identified by nomogram.

Results: There were 7582 eligible patients; 6066 received preoperative radiotherapy, and 1516 received non-preoperative radiotherapy. The initial result showed that the pooled hazard ratio (HR) for OS was in favor of preoperative radiotherapy compared with non-preoperative radiotherapy group (HR $=0.86,95 \%$ confidence interval $(\mathrm{Cl})=0.75-0.98, \mathrm{P}<0.05)$. The cases were randomly divided into training and validation datasets, and multivariate Cox regression analysis of the training set determined that age, sex, carcinoembryonic antigen level, tumor stage, node stage, tumor differentiation, perineural invasion, and the number of dissected lymph nodes were independent risk factors for OS in the training set (all $P$ $<0.05$ ). A nomogram was established based on the risk factors to predict the OS (concordance index, training set: 0.70 , validation set: 0.67$)$. Further analysis showed that the long-term survival of high-risk patients was better with preoperative radiotherapy $(\mathrm{HR}=0.71,95 \% \mathrm{Cl}=0.56-0.91, \mathrm{P}<0.05)$.

Conclusions: Preoperative radiotherapy has long-term survival benefits for LARC patients, especially those with high risk.

\section{Background}

Colorectal cancer is one of the most common malignant cancers worldwide and the second leading cause of cancer mortality globally [1]. In the United States, 43340 new patients were diagnosed with rectal cancer, including 25960 men and 17380 women in 2020 [2]. Nonetheless, rectal cancer has steadily decreased in recent decades [2,3], and the mortality rate is down by approximately $50 \%$ from the peak, perhaps owing to earlier diagnoses by screening and comprehensive treatment [4].

Radiation-based neoadjuvant therapy following radical surgery has been the standard treatment for locally advanced rectal cancer (LARC) [5, 6], but the long-term survival benefit has never been established $[7,8]$. The advent of the total mesorectal excision (TME) has decreased the local recurrence rate to approximately $9 \%$, even lower if intensified radiotherapy is applied [9-14]. Currently, treatment failure primarily presents as distant metastasis rather than local recurrence $[7,8,15,16]$.

In 2019, a retrospective study based on the Surveillance, Epidemiology, and End Results (SEER) database verified the preoperative radiotherapy survival benefit in 49439 patients, but the study had a critical 
limitation. The study span, ranging from 1988-2011, was too long to avoid confounding factors. The surgical technique evolved (from local excision to TME), radiation therapy progressed (from convention radiotherapy to intensity-modulated radiation therapy), and the timeframe of intensive chemotherapy shifted (from postoperative to preoperative) [17]. Therefore, the effects of preoperative radiotherapy on the long-term survival benefits are still unclear.

This study analyzed patients from the SEER database diagnosed between 2011 and 2015 to re-evaluate the clinical value of radiation-based neoadjuvant therapies in the TME era and identify candidates who may benefit from radiation-based neoadjuvant therapy in long-term survival. This study also summarized phase III randomized clinical trials (RCTs) to elucidate long-term survival failure reasons.

\section{Methods}

\section{Data source and patient selection}

The SEER database was screened for patients diagnosed with rectal cancer between 2011 and 2015 using SEER*Stat software (version 8.3.8) with the International Classification of Diseases for Oncology $3^{\text {rd }}$ Edition (ICD-0-3) code: C20.9 Rectum, NOS. Rectal cancer cases were retrieved based on the following: adenocarcinoma (ICD-0-3 codes: 8140/3, 8144/3, 8210/3, 8221/3, 8255/3, 8263/3, and $8572 / 3)$; stage T3-4 or $\mathrm{N}+$ and M0 tumors (derived from derived AJCC T, $7^{\text {th }}$ ed (2010-2015), derived AJCC N, $7^{\text {th }}$ ed (2010-2015) and derived AJCC M, $7^{\text {th }}$ ed (2010-2015)); received surgery, including lymphadenectomy (derived from reason no cancer-directed surgery, and regional nodes examined examination (1988+)); and underwent chemotherapy (derived from chemotherapy recode). Cases were excluded if there were multiple primary tumors or no preoperative radiotherapy records. All patients underwent active follow-ups. The T/N classification was re-staged according to the $8^{\text {th }}$ edition of the American Joint Committee on Cancer (AJCC) staging system with the following codes: derived AJCC T, $7^{\text {th }}$ ed. (2010-2015); derived AJCC N, $7^{\text {th }}$ ed. (2010-2015); CS extension (2004-2015); CS lymph nodes (2004-2015); and CS site-specific factor 4 (2004+ varying by schema). The endpoint was overall survival (OS), which was extracted directly from the database as months.

\section{Variable definitions and stratification}

The data were collected and re-categorized as follows: age at diagnosis ( $\leq 65$ years, $>65$ years), sex (male, female), insurance (no, yes), serum carcinoembryonic antigen (CEA) level ( $\leq 5 \mathrm{ng} / \mathrm{mL},>5 \mathrm{ng} / \mathrm{mL}$ ), stage (II, III), T stage (T0/T1/T2, T3, T4), N stage (N0, N1, N2), tumor differentiation (I/II, III/IV), tumor size ( $\leq 3 \mathrm{~cm}, 3-5 \mathrm{~cm},>5 \mathrm{~cm}$ ), tumor deposits (negative, positive), perineural invasion status (absent, present), number of dissected lymph nodes (LND) $(<12, \geq 12)$, preoperative radiotherapy (no, yes), and survival (months).

\section{Statistical analyses}


Continuous variables were re-defined as categorical variables and presented as $\mathrm{n}(\%)$. Kaplan-Meier curves were plotted to compare the survival difference between patients who received preoperative radiotherapy and those who did not (presented with hazard ratios [HR] and 95\% confidence intervals $[\mathrm{Cl}]$ ). Subgroup analysis among patients who received or did not receive preoperative radiotherapy were further stratified by variable and plotted using a forest map.

The entire data set was randomly divided into training and validation sets at a 6:4 ratio and compared using the chi-square test or Fisher's test. A nomogram was established based on the multivariate analysis results, which integrated all of the independent prognostic factors. A calibration plot was constructed to evaluate the calibration of the nomogram. Harrell's concordance index (C-index) and the area under the receiver operating characteristic curve (AUC) were used to assess the predictive outcome performance of the nomogram and the outcomes. The clinical utility of the nomogram was also evaluated using decision curve analysis (DCA), which included the continuous risk of the probability threshold ( $x$-axis) and the net benefit (y-axis). The nomogram was also compared with the $8^{\text {th }}$ AJCC staging system.

Statistical tests were conducted using RStudio (version 1.3.1073), including the xlsx, table1, survminer, survival, forestplot, rms, nomogramFormula, timeROC, stdca, and survcomp packages. All statistical tests were two-tailed, and statistical significance was set to $P<0.05$.

\section{Results}

\section{Patient characteristics}

There were 7582 eligible patients according to the predesigned flow chart (Additional File 1: Figure S1), and their baseline characteristics are presented in Table $1 ; 6066$ patients $(80.0 \%)$ received preoperative radiotherapy, and 1516 patients $(20.0 \%)$ did not. There were 2752 patients $(36.3 \%)$ at stage II and 4817 (63.5\%) at stage III according to the $8^{\text {th }}$ AJCC staging system. In addition, $73.5 \%$ of patients had $\geq 12$ LND.

\section{The effect of preoperative radiotherapy on LARC patients' long-term survival}

For the entire dataset (training and validation), the Kaplan-Meier survival curve showed that the pooled HR for the median OS favored preoperative radiotherapy instead of surgery without preoperative radiotherapy $(\mathrm{HR}=0.86,95 \% \mathrm{Cl}=0.75-0.98, \mathrm{P}=0.028$, Figure 1$)$. The 3 - and 5 -year survival rates with or without preoperative radiotherapy were all over 70\% (with: 3-year, 86.9\%, 5-year: 84.8\%; without: 3-year, $74.9 \%, 5$-year, 72.5\%). Univariate and multivariate Cox regression analysis showed that preoperative radiotherapy was not an independent risk factor for OS $(\mathrm{HR}=0.97,95 \% \mathrm{Cl}=0.80-1.17, \mathrm{P}=0.728)$.

\section{Subgroup analysis of OS stratified by risk factor}

Using the entire dataset, stratified subgroup analysis showed that patients with the following risk factors benefited from preoperative radiotherapy regarding OS (Figure 2): aged $>65$ years $(\mathrm{HR}=0.75,95 \% \mathrm{Cl}=$ 
$0.61-0.92, \mathrm{P}=0.005)$, stage III $(\mathrm{HR}=0.83,95 \% \mathrm{Cl}=0.71-0.97, \mathrm{P}=0.020), \mathrm{T} 3(\mathrm{HR}=0.81,95 \% \mathrm{Cl}=0.69-$ $0.95, \mathrm{P}=0.010), \mathrm{T} 4(\mathrm{HR}=0.70,95 \% \mathrm{Cl}=0.51-0.95, \mathrm{P}=0.020), \mathrm{N} 2(\mathrm{HR}=0.62,95 \% \mathrm{Cl}=0.48-0.80, \mathrm{P}$ $<0.001)$, tumor size $>5 \mathrm{~cm}(\mathrm{HR}=0.71,95 \% \mathrm{Cl}=0.57-0.88, \mathrm{P}=0.002)$, tumor deposits $(\mathrm{HR}=0.77,95 \% \mathrm{Cl}=$ $0.59-0.99, \mathrm{P}=0.042)$, and $L N D \geq 12(\mathrm{HR}=0.81,95 \% \mathrm{Cl}=0.69-0.95, \mathrm{P}=0.008)$.

\section{Nomogram construction for LARC prognosis}

The entire dataset was randomly divided into training and validation sets (6:4 ratio, Additional File 2, Table S1). The univariate and multivariate Cox regression results for the training set are presented in Table 2. Age >65 years, CEA >5 ng/mL, T3, T4, N2, tumor differentiation III/IV, and perineural invasion were independent risk factors for OS (all P <0.05), while female and LND $\geq 12$ were independent protective factors for OS (both $\mathrm{P}<0.05$ ). A prognostic nomogram was developed based on the multivariate Cox regression results to predict the 1-, 3-, and 5-year survival rates (Figure 3).

\section{Nomogram predictive performance}

The C-index of the nomogram was 0.70 in the training set $(95 \% \mathrm{Cl}=0.67-0.72)$ and 0.67 in the validation set $(95 \% \mathrm{Cl}=0.63-0.71)$, which were higher than the $8^{\text {th }}$ AJCC staging system (training set: $0.63,95 \% \mathrm{Cl}=$ 0.60-0.67, $\mathrm{P}<0.001$; validation set: $0.61,95 \% \mathrm{Cl}=0.56-0.66, \mathrm{P}=0.005$; Table 3 ). The nomogram also had better discrimination compared to the $8^{\text {th }}$ AJCC staging system using time-dependent AUC analysis. The 1-, 3-, and 5-year AUC with 95\% Cls for different models are presented in Table 3. Additionally, there was good consistency between the observed and the predicted outcomes of the nomogram regarding 3- and 5 -year OS in the training and validation sets using calibration plots (Figure 4). DCA also showed that the nomogram had better net benefits at the 5-year mark than the $8^{\text {th }}$ AJCC staging system in the training (Figure 5A) and validation sets (Figure 5B).

\section{Clinical application of the nomogram}

Each patient's total score was determined based on the nomogram. The median total score for the entire dataset was 129 (range: 24-296). A score of 158 was set as the cut-off value to divide patients into highand low-risk groups. There were 1224 patients in the high-risk group, which had a shorter median OS than the low-risk group $(\mathrm{HR}=2.62,95 \% \mathrm{Cl}=2.25-3.04, \mathrm{P}<0.001$, Figure $6 \mathrm{~A})$. Further analysis showed that there were no differences between the low-risk groups with and without preoperative radiotherapy $(H R=1.19$, $95 \% \mathrm{Cl}=0.92-1.54, \mathrm{P}=0.180$, Figure $6 \mathrm{~B}$ ), but significantly prolonged median OS in the high-risk group who received preoperative radiotherapy $(\mathrm{HR}=0.71,95 \% \mathrm{Cl}=0.56-0.91, \mathrm{P}=0.006$, Figure $6 \mathrm{C})$.

\section{Discussion}

This is the first retrospective population-based study to evaluate the effect of radiation-based neoadjuvant treatments on the long-term prognosis of LARC patients in the TME era. Patients who received preoperative radiotherapy had a significantly prolonged OS and a slightly higher 5-year survival rate compared to those without. The nomogram, constructed based on the multivariate Cox regression 
analysis, predicted the prognosis better than the 8th AJCC staging system and showed that high-risk patients are more likely to benefit from preoperative radiotherapy, as indicated by their OS.

Radiotherapy was initially introduced as an adjuvant treatment to prevent local rectal cancer recurrence $[18,19]$. Later on, radiotherapy was tested as a preoperative treatment, resulting in stronger antirecurrence efficacies, higher $\mathrm{R} 0$ resection rate, increased sphincter-preserving, and less radiation toxicity $[7,13,20,21]$. Generally, radiation based neoadjuvant therapies, including long-course radiotherapy (LCRT) combined with concurrent chemotherapy and short-course radiotherapy (SCRT), followed by instant or delayed surgery, have been the standard treatment for patients with LARC $[13,22,23]$. Numerous single-center and multi-center trials have laid the foundation for radiation-based neoadjuvant treatment for LARC management, which is now used in clinics worldwide. In this study, $80.0 \%$ of LARC patients received radiation-based neoadjuvant treatment.

However, there has always been controversy regarding preoperative radiotherapy. First, the pathological complete response $(\mathrm{PCR})$ rate following radiation-based neoadjuvant treatments varies different from different modalities (LCRT: 2.2 to $33.8 \%$; SCRT: 0.3 to 28.0\%) [15, 22, 24-27]. Second, acute radiationinduced injury, such as radiation colitis, decreases treatment compliance and quality of life [28-30]. Third, late radiation-induced injury, such as fibrosis, increases the surgical dissection difficulty and the risk for postoperative complications [31, 32]. Ultimately, the long-term survival benefit (e.g., disease-free survival [DFS] and OS) of radiation-based neoadjuvant treatments (regardless of the modality) is not clear. Since the start of TME, the primary treatment failure indicator is distant metastasis rather than local recurrence, suggesting that the clinical value of preoperative radiotherapy for LARC management needs re-evaluation.

The key to correctly evaluate the clinical efficacy of a treatment modality is endpoint selection. $\mathrm{PCR}$ is the most widely used endpoint to evaluate neoadjuvant treatments, but using PCR as an optimal surrogate endpoint remains controversial [33]. This may be because the correlation between PCR and long-term survival is not definite [34-37], and pCR is influenced by other non-treatment factors (e.g., the interval between radiotherapy completion and surgery) $[38,39]$. DFS is the time from randomization to recurrence or death from any cause [40], which was found to be a stronger predictor of OS than pCR among 2795 patients receiving neoadjuvant treatment [41]. However, DFS is also not an ideal surrogate endpoint because the DFS starting time varies, especially regarding surgery. OS is a hard endpoint for any treatment, although it has been confounded by salvage treatments (in recurrence cases) and potential causes of non-cancer-related mortality. OS also often requires a larger sample size, longer follow-up, and higher costs. Radiation-based neoadjuvant treatment advantages on the OS were rarely observed among phase III RCTs (Table 4) [8, 10,42-49], but advantages were identified in a meta-analysis including 6426 trial patients in 2000 and a population-based analysis including 49439 patients in 2019 [17, 50]. The most likely reason for this divergence was the sample size.

In the TME era, local recurrence is no more than a primary cause of treatment failure. Intensified neoadjuvant chemotherapy was also found to be comparable to radiation-based neoadjuvant treatments 
in terms of OS, and even had a weak DFS advantage [51,52]. Both of above have caused the necessity of preoperative radiotherapy to be questioned. In this study, 7582 patients between 2011 and 2015 from the SEER database were eligible for survival analysis, and the pooled HR for the median OS favored the preoperative radiotherapy group compared to the group without preoperative radiotherapy. In addition, a nomogram was developed to predict the long-term prognosis of LARC patients with better calibration than the 8th AJCC staging system and a significantly higher C-index. The nomogram also indicated that high-risk patients would benefit from preoperative radiotherapy more than low-risk patients regarding long-term survival. Therefore, we concluded that radiation-based neoadjuvant treatments should been conducted in the management of LARC patients in the era of TME and intensified chemotherapy.

From the other hand, watch and wait strategy has been pouring new vigor into the application of preoperative radiotherapy. Although radical surgery followed by neoadjuvant treatment is the standard treatment for LARC patients, there are two kinds of particular cases. Some patients are reluctant to undergo surgery, and some are not tolerant to surgery. A retrospective study analyzed 71 patients with a complete clinical response using the "watch and wait" strategy and 21 patients with an incomplete clinical response but a complete pathologic response post-TME [53]. The 5-year OS and DFS rates were $100 \%$ and $92 \%$ in the "watch and wait" group, and $88 \%$ and $83 \%$ in the surgery group, respectively. The "watch and wait" advantage was also confirmed in a study by three neighboring UK regional cancer centers that used a propensity score-matched cohort to analyze the 3-year rates of non-regrowth DFS (wait: $88 \%$, surgery: $78 \%$ ), OS (wait: $96 \%$, surgery: $87 \%$ ), and colostomy-free survival (wait: $74 \%$, surgery: 47\%) [54]. In a retrospective study of 3298 patients receiving neoadjuvant chemoradiotherapy, pCR was found to be significantly associated with the radiotherapy dose [55]. A prospective single-arm study including 55 patients reported that the clinical complete response rate was up to $73 \%$ using high-dose chemoradiotherapy (60 Gy/30 fractions) [56]. Hence, multidisciplinary management combined with patient willingness is strongly recommended to make decision for LARC patients, and intensified curative chemoradiotherapy may be an alternative for select patients.

This study has several limitations. First, this was a retrospective study. Second, preoperative radiotherapy data, including modality, gross tumor volume, clinical target volume, dose, and combination with chemotherapy, were not available. Third, chemotherapy administration before or after surgery is unknown. Although, LCRT is preferred in the USA, and chemotherapy is increasingly suggested. Finally, the TME technique has been popular worldwide since 2002 [57-60] and we only enrolled patients after 2010 , but data on surgery in the SEER database were unavailable.

\section{Conclusion}

Preoperative radiotherapy may bring long-term survival benefits for LARC patients, but further validation with a larger sample size and multi-center RCTs with well-designed outcome measurements is required.

\section{Abbreviations}


LARC: locally advanced rectal cancer

TME: total mesorectal excision

SEER: Surveillance, Epidemiology, and End Results

RCT: randomized clinical trials

AJCC: American Joint Committee on Cancer

T: primary tumor

$\mathrm{N}$ : Regional Lymph Nodes

OS: overall survival

CEA: carcinoembryonic antigen

LND: dissected lymph nodes

HR: hazard ratio

Cl: confidence interval

C-index: Harrell's concordance index

AUC: area under the receiver operating characteristic curve

DCA: decision curve analysis

LCRT: long-course radiotherapy

SCRT: short-course radiotherapy

pCR: pathological complete response

DFS: disease-free survival

\section{Declarations}

\section{Ethics approval and consent to participate:}

The ethical committee waved away the informed consent, due to that all the data was derived from public database and individual information was anonymous.

Consent for publication: 
Not applicable.

\section{Availability of data and materials:}

The datasets analyzed in this study are obtained from SEER database and can be obtained from: https://seer.cancer.gov/data/. The data are also available by contacting the corresponding author on reasonable request.

\section{Competing interests:}

The authors declare that they have no competing interests.

\section{Funding:}

This research was funded by the Fujian Province Natural Science Foundation (grant number 2017J01260); the Joint Funds for the Innovation of Science and Technology, Fujian Province (grant number 2017Y9074); the Fujian Province Finance Department Project (No. (2015)1249); the Fujian Province Finance Department Project (No. (2015)790); the Startup Fund for scientific research, Fujian Medical University खgrant number 2019QH1198).

\section{Authors' contributions:}

$\mathrm{LW} \square \mathrm{XHZ} \square \mathrm{HQL}$ contributed to conception and design. XHZ $\mathrm{HQL}$ conducted data collection and analyzed the data. LW drafted the manuscript. XQZ, LDS, JXW contributed critical revision of the manuscript. All authors read and approved the final manuscript.

\section{Acknowledgements:}

We thank the SEER database for providing valuable and public datasets.

\section{References}

1. Sung H, Ferlay J, Siegel RL, Laversanne M, Soerjomataram I, Jemal A, et al. Global cancer statistics 2020: GLOBOCAN estimates of incidence and mortality worldwide for 36 cancers in 185 countries. CA Cancer J Clin. 2021.

2. Siegel RL, Miller KD, Jemal A. Cancer statistics, 2020. CA Cancer J Clin. 2020;70(1):7-30.

3. Cheng L, Eng C, Nieman LZ, Kapadia AS, Du XL. Trends in colorectal cancer incidence by anatomic site and disease stage in the United States from 1976 to 2005. Am J Clin Oncol. 2011;34(6):573-80.

4. Benson AB, Venook AP, Al-Hawary MM, Arain MA, Chen YJ, Ciombor KK, et al. NCCN Guidelines Insights: Rectal Cancer, Version 6.2020. J Natl Compr Canc Netw. 2020;18(7):806-15.

5. Benson AB, Venook AP, Al-Hawary MM, Cederquist L, Chen YJ, Ciombor KK, et al. Rectal Cancer, Version 2.2018, NCCN Clinical Practice Guidelines in Oncology. J Natl Compr Canc Netw. 2018;16(7):874-901. 
6. Glynne-Jones R, Wyrwicz L, Tiret E, Brown G, Rödel C, Cervantes A, et al. Rectal cancer: ESMO Clinical Practice Guidelines for diagnosis, treatment and follow-up. Ann Oncol. 2017;28(suppl_4): iv22-iv40.

7. Sauer R, Liersch T, Merkel S, Fietkau R, Hohenberger W, Hess C, et al. Preoperative versus postoperative chemoradiotherapy for locally advanced rectal cancer: results of the German CAO/ARO/AIO-94 randomized phase III trial after a median follow-up of 11 years. J Clin Oncol. 2012;30(16):1926-33.

8. van Gijn W, Marijnen CA, Nagtegaal ID, Kranenbarg EM, Putter H, Wiggers T, et al. Preoperative radiotherapy combined with total mesorectal excision for resectable rectal cancer: 12-year follow-up of the multicentre, randomised controlled TME trial. Lancet Oncol. 2011;12(6):575-82.

9. Heald RJ, Moran BJ, Ryall RD, Sexton R, MacFarlane JK. Rectal cancer: the Basingstoke experience of total mesorectal excision, 1978-1997. Arch Surg. 1998;133(8):894-9.

10. Kapiteijn E, Marijnen CA, Nagtegaal ID, Putter H, Steup WH, Wiggers T, et al. Preoperative radiotherapy combined with total mesorectal excision for resectable rectal cancer. N Engl J Med. 2001;345(9):63846.

11. Kapiteijn E, Putter H, van de Velde CJ. Impact of the introduction and training of total mesorectal excision on recurrence and survival in rectal cancer in The Netherlands. Br J Surg. 2002;89(9):1142-9.

12. Kosinski L, Habr-Gama A, Ludwig K, Perez R. Shifting concepts in rectal cancer management: a review of contemporary primary rectal cancer treatment strategies. CA Cancer J Clin. 2012;62(3):173202.

13. Sauer R, Becker H, Hohenberger W, Rödel C, Wittekind C, Fietkau R, et al. Preoperative versus postoperative chemoradiotherapy for rectal cancer. N Engl J Med. 2004;351(17):1731-40.

14. Smith JJ, Garcia-Aguilar J. Advances and challenges in treatment of locally advanced rectal cancer. J Clin Oncol. 2015;33(16):1797-808.

15. Bahadoer RR, Dijkstra EA, van Etten B, Marijnen CAM, Putter H, Kranenbarg EM, et al. Short-course radiotherapy followed by chemotherapy before total mesorectal excision (TME) versus preoperative chemoradiotherapy, TME, and optional adjuvant chemotherapy in locally advanced rectal cancer (RAPIDO): a randomised, open-label, phase 3 trial. Lancet Oncol. 2021;22(1):29-42.

16. Frambach P, Pucciarelli S, Perin A, Zuin M, Toppan P, Maretto I, et al. Metastatic pattern and new primary tumors after neoadjuvant therapy and surgery in rectal cancer. Colorectal Dis. 2018;20(12): 0326-034.

17. Wang R, Zhao D, Liu YJ, Ye C, Qian JR, Dai JN, et al. Prognostic significance of preoperative radiotherapy in stage II and III rectal cancer patients: A Strobe-compliant study of SEER 18 registries database (1988-2011). Neoplasma. 2019;66(6):995-1001.

18. Prolongation of the disease-free interval in surgically treated rectal carcinoma. N Engl J Med. 1985;312(23):1465-72.

19. Effective surgical adjuvant therapy for high-risk rectal carcinoma. N Engl J Med. 1991;325(7):519-20.

20. Park JH, Yoon SM, Yu CS, Kim JH, Kim TW, Kim JC. Randomized phase 3 trial comparing preoperative and postoperative chemoradiotherapy with capecitabine for locally advanced rectal 
cancer. Cancer. 2011;117(16):3703-12.

21. Roh MS, Colangelo LH, O'Connell MJ, Yothers G, Deutsch M, Allegra CJ, et al. Preoperative multimodality therapy improves disease-free survival in patients with carcinoma of the rectum: NSABP R-03. J Clin Oncol. 2009;27(31):5124-30.

22. Ciseł B, Pietrzak L, Michalski W, Wyrwicz L, Rutkowski A, Kosakowska E, et al. Long-course preoperative chemoradiation versus $5 \times 5 \mathrm{~Gy}$ and consolidation chemotherapy for clinical T4 and fixed clinical T3 rectal cancer: long-term results of the randomized Polish II study. Ann Oncol. 2019;30(8):1298-303.

23. Ngan SY, Burmeister B, Fisher RJ, Solomon M, Goldstein D, Joseph D, et al. Randomized trial of shortcourse radiotherapy versus long-course chemoradiation comparing rates of local recurrence in patients with T3 rectal cancer: Trans-Tasman Radiation Oncology Group trial 01.04. J Clin Oncol. 2012;30(31):3827-33.

24. Erlandsson J, Lörinc E, Ahlberg M, Pettersson D, Holm T, Glimelius B, et al. Tumour regression after radiotherapy for rectal cancer - Results from the randomised Stockholm III trial. Radiother Oncol. 2019;135:178-86.

25. Rödel C, Graeven U, Fietkau R, Hohenberger W, Hothorn T, Arnold D, et al. Oxaliplatin added to fluorouracil-based preoperative chemoradiotherapy and postoperative chemotherapy of locally advanced rectal cancer (the German CAO/ARO/AIO-04 study): final results of the multicentre, openlabel, randomised, phase 3 trial. Lancet Oncol. 2015;16(8):979-89.

26. Zhu J, Liu A, Sun X, Liu L, Zhu Y, Zhang T, et al. Multicenter, Randomized, Phase III Trial of Neoadjuvant Chemoradiation With Capecitabine and Irinotecan Guided by UGT1A1 Status in Patients With Locally Advanced Rectal Cancer. J Clin Oncol. 2020;38(36):4231-9.

27. Bujko K, Nowacki MP, Nasierowska-Guttmejer A, Michalski W, Bebenek M, Kryj M. Long-term results of a randomized trial comparing preoperative short-course radiotherapy with preoperative conventionally fractionated chemoradiation for rectal cancer. Br J Surg. 2006;93(10):1215-23.

28. Chen TY, Wiltink LM, Nout RA, Meershoek-Klein Kranenbarg E, Laurberg S, Marijnen CA, et al. Bowel function 14 years after preoperative short-course radiotherapy and total mesorectal excision for rectal cancer: report of a multicenter randomized trial. Clinical colorectal cancer. 2015;14(2):106-14.

29. Haynes AB, You YN, Hu CY, Eng C, Kopetz ES, Rodriguez-Bigas MA, et al. Postoperative chemotherapy use after neoadjuvant chemoradiotherapy for rectal cancer: Analysis of Surveillance, Epidemiology, and End Results-Medicare data, 1998-2007. Cancer. 2014;120(8):1162-70.

30. Wiltink LM, Marijnen CA, Meershoek-Klein Kranenbarg E, van de Velde CJ, Nout RA. A comprehensive longitudinal overview of health-related quality of life and symptoms after treatment for rectal cancer in the TME trial. Acta Oncol. 2016;55(4):502-8.

31. Keller DS, Berho M, Perez RO, Wexner SD, Chand M. The multidisciplinary management of rectal cancer. Nat Rev Gastroenterol Hepatol. 2020;17(7):414-29.

32. Lefevre JH, Mineur L, Kotti S, Rullier E, Rouanet P, de Chaisemartin C, et al. Effect of Interval (7 or 11 weeks) Between Neoadjuvant Radiochemotherapy and Surgery on Complete Pathologic Response in 
Rectal Cancer: A Multicenter, Randomized, Controlled Trial (GRECCAR-6). J Clin Oncol. 2016;34(31):3773-80.

33. Fokas E, Glynne-Jones R, Appelt A, Beets-Tan R, Beets G, Haustermans K, et al. Outcome measures in multimodal rectal cancer trials. Lancet Oncol. 2020;21(5):e252-e64.

34. Bonnetain F, Bosset JF, Gerard JP, Calais G, Conroy T, Mineur L, et al. What is the clinical benefit of preoperative chemoradiotherapy with $5 \mathrm{FU} /$ leucovorin for T3-4 rectal cancer in a pooled analysis of EORTC 22921 and FFCD 9203 trials: surrogacy in question? Eur J Cancer. 2012;48(12):1781-90.

35. Maas M, Nelemans PJ, Valentini V, Das P, Rödel C, Kuo LJ, et al. Long-term outcome in patients with a pathological complete response after chemoradiation for rectal cancer: a pooled analysis of individual patient data. Lancet Oncol. 2010;11(9):835-44.

36. Methy N, Bedenne L, Conroy T, Bouché O, Chapet O, Ducreux M, et al. Surrogate end points for overall survival and local control in neoadjuvant rectal cancer trials: statistical evaluation based on the FFCD 9203 trial. Ann Oncol. 2010;21(3):518-24.

37. Petrelli F, Borgonovo K, Cabiddu M, Ghilardi M, Lonati V, Barni S. Pathologic complete response and disease-free survival are not surrogate endpoints for 5-year survival in rectal cancer: an analysis of 22 randomized trials. J Gastrointest Oncol. 2017;8(1):39-48.

38. Akgun E, Caliskan C, Bozbiyik O, Yoldas T, Sezak M, Ozkok S, et al. Randomized clinical trial of short or long interval between neoadjuvant chemoradiotherapy and surgery for rectal cancer. Br J Surg. 2018;105(11):1417-25.

39. Francois Y, Nemoz CJ, Baulieux J, Vignal J, Grandjean JP, Partensky C, et al. Influence of the interval between preoperative radiation therapy and surgery on downstaging and on the rate of sphinctersparing surgery for rectal cancer: the Lyon R90-01 randomized trial. J Clin Oncol. 1999;17(8):2396.

40. Punt CJ, Buyse M, Köhne $\mathrm{CH}$, Hohenberger P, Labianca R, Schmoll HJ, et al. Endpoints in adjuvant treatment trials: a systematic review of the literature in colon cancer and proposed definitions for future trials. J Natl Cancer Inst. 2007;99(13):998-1003.

41. Valentini V, van Stiphout RG, Lammering G, Gambacorta MA, Barba MC, Bebenek M, et al. Selection of appropriate end-points ( $\mathrm{pCR}$ vs 2yDFS) for tailoring treatments with prediction models in locally advanced rectal cancer. Radiother Oncol. 2015;114(3):302-9.

42. Roswit B, Higgins GA, Keehn RJ. Preoperative irradiation for carcinoma of the rectum and rectosigmoid colon: reportof a National Veterans Administration randomized study. Cancer. 1975;35(6):1597-602.

43. Higgins GA, Humphrey EW, Dwight RW, Roswit B, Lee LE, Jr., Keehn RJ. Preoperative radiation and surgery for cancer of the rectum. Veterans Administration Surgical Oncology Group Trial II. Cancer. 1986;58(2):352-9.

44. Gérard A, Buyse M, Nordlinger B, Loygue J, Pène F, Kempf P, et al. Preoperative radiotherapy as adjuvant treatment in rectal cancer. Final results of a randomized study of the European Organization for Research and Treatment of Cancer (EORTC). Ann Surg. 1988;208(5):606-14. 
45. Preoperative short-term radiation therapy in operable rectal carcinoma. A prospective randomized trial. Stockholm Rectal Cancer Study Group. Cancer. 1990;66(1):49-55.

46. Goldberg PA, Nicholls RJ, Porter NH, Love S, Grimsey JE. Long-term results of a randomised trial of short-course low-dose adjuvant pre-operative radiotherapy for rectal cancer: reduction in local treatment failure. Eur J Cancer. 1994;30a(11):1602-6.

47. Marsh PJ, James RD, Schofield PF. Adjuvant preoperative radiotherapy for locally advanced rectal carcinoma. Results of a prospective, randomized trial. Dis Colon Rectum. 1994;37(12):1205-14.

48. Randomised trial of surgery alone versus radiotherapy followed by surgery for potentially operable locally advanced rectal cancer. Medical Research Council Rectal Cancer Working Party. Lancet. 1996;348(9042):1605-10.

49. Cedermark B, Dahlberg M, Glimelius B, Påhlman L, Rutqvist LE, Wilking N. Improved survival with preoperative radiotherapy in resectable rectal cancer. N Engl J Med. 1997;336(14):980-7.

50. Cammà C, Giunta M, Fiorica F, Pagliaro L, Craxì A, Cottone M. Preoperative radiotherapy for resectable rectal cancer: A meta-analysis. Jama. 2000;284(8):1008-15.

51. Deng Y, Chi P, Lan P, Wang L, Chen W, Cui L, et al. Neoadjuvant Modified FOLFOX6 With or Without Radiation Versus Fluorouracil Plus Radiation for Locally Advanced Rectal Cancer: Final Results of the Chinese FOWARC Trial. J Clin Oncol. 2019;37(34):3223-33.

52. Conroy T, Lamfichekh N, Etienne P-L, Rio E, FRANCOIS E, Mesgouez-Nebout N et al. Total neoadjuvant therapy with mFOLFIRINOX versus preoperative chemoradiation in patients with locally advanced rectal cancer: Final results of PRODIGE 23 phase III trial, a UNICANCER GI trial2020. ASCO. 2020.

53. Habr-Gama A, Perez RO, Nadalin W, Sabbaga J, Ribeiro U, Jr., Silva e Sousa AH, Jr., et al. Operative versus nonoperative treatment for stage 0 distal rectal cancer following chemoradiation therapy: long-term results. Ann Surg. 2004;240(4):711-7; discussion 7-8.

54. Renehan AG, Malcomson L, Emsley R, Gollins S, Maw A, Myint AS, et al. Watch-and-wait approach versus surgical resection after chemoradiotherapy for patients with rectal cancer (the OnCoRe project): a propensity-score matched cohort analysis. Lancet Oncol. 2016;17(2):174-83.

55. Hall MD, Schultheiss TE, Smith DD, Fakih MG, Wong JY, Chen YJ. Effect of increasing radiation dose on pathologic complete response in rectal cancer patients treated with neoadjuvant chemoradiation therapy. Acta Oncol. 2016;55(12):1392-9.

56. Appelt AL, Pløen J, Harling H, Jensen FS, Jensen LH, Jørgensen JC, et al. High-dose chemoradiotherapy and watchful waiting for distal rectal cancer: a prospective observational study. Lancet Oncol. 2015;16(8):919-27.

57. Havenga K, Enker WE. Autonomic nerve preserving total mesorectal excision. Surg Clin North Am. 2002;82(5):1009-18.

58. Heald RJ, Husband EM, Ryall RD. The mesorectum in rectal cancer surgery-the clue to pelvic recurrence? Br J Surg. 1982;69(10):613-6. 
59. Lange MM, Rutten HJ, van de Velde CJ. One hundred years of curative surgery for rectal cancer: 1908-2008. Eur J Surg Oncol. 2009;35(5):456-63.

60. Maas CP, Moriya Y, Steup WH, Klein Kranenbarg E, van de Velde CJ. A prospective study on radical and nerve-preserving surgery for rectal cancer in the Netherlands. Eur J Surg Oncol. 2000;26(8):7517.

\section{Tables}


Table 1

Demographic and tumor characteristics of 7582 rectal cancer patients

\begin{tabular}{|c|c|c|}
\hline Character & $\mathrm{n}$ & $\%$ \\
\hline Sample size & 7582 & 100.0 \\
\hline \multicolumn{3}{|l|}{ Age } \\
\hline$\leq 65$ years & 5421 & 71.5 \\
\hline$>65$ years & 2161 & 28.5 \\
\hline \multicolumn{3}{|l|}{ Sex } \\
\hline Male & 4649 & 61.3 \\
\hline Female & 2933 & 38.7 \\
\hline \multicolumn{3}{|l|}{ Insurance } \\
\hline No & 299 & 3.9 \\
\hline Yes & 7200 & 95.0 \\
\hline Unknown & 83 & 1.1 \\
\hline \multicolumn{3}{|l|}{ CEA } \\
\hline$\leq 5 \mathrm{ng} / \mathrm{mL}$ & 3047 & 40.2 \\
\hline$>5 \mathrm{ng} / \mathrm{mL}$ & 2300 & 30.3 \\
\hline Unknown & 2235 & 29.5 \\
\hline \multicolumn{3}{|l|}{ Stage } \\
\hline II & 2752 & 36.3 \\
\hline III & 4817 & 63.5 \\
\hline Unknown & 13 & 0.2 \\
\hline \multicolumn{3}{|l|}{ T stage } \\
\hline $\mathrm{T0} / \mathrm{T} 1 / \mathrm{T} 2$ & 670 & 8.8 \\
\hline T3 & 6065 & 80.0 \\
\hline T4 & 804 & 10.6 \\
\hline Unknown & 43 & 0.6 \\
\hline
\end{tabular}




\begin{tabular}{|lll|}
\hline Character & $\mathbf{n}$ & $\mathbf{\%}$ \\
\hline N0 & 2671 & 35.2 \\
\hline N1 & 3787 & 49.9 \\
\hline N2 & 1111 & 14.7 \\
\hline Unknown & 13 & 0.2 \\
\hline Tumor differentiation & & \\
\hline Grade I/II & 5961 & 78.6 \\
\hline Grade III/IV & 827 & 10.9 \\
\hline Unknown & 794 & 10.5 \\
\hline Tumor size & & \\
\hline$\leq 3$ cm & 1811 & 23.9 \\
\hline $3-5$ cm & 2570 & 33.9 \\
\hline$>5$ cm & 2220 & 29.3 \\
\hline Unknown & 981 & 12.9 \\
\hline Tumor deposits & & \\
\hline Negative & 6094 & 80.3 \\
\hline Positive & 961 & 12.7 \\
\hline Unknown & 527 & 7.0 \\
\hline
\end{tabular}


Table 1

(Continued)

\begin{tabular}{|lll|}
\hline Character & $\mathbf{n}$ & \% \\
\hline Perineural invasion & & \\
\hline Absent & 5876 & 77.5 \\
\hline Present & 903 & 11.9 \\
\hline Unknown & 803 & 10.6 \\
\hline Number of LND & & \\
\hline$<12$ & 1992 & 26.3 \\
\hline$\geq 12$ & 5577 & 73.5 \\
\hline Unknown & 13 & 0.2 \\
\hline Preoperative radiotherapy & & \\
\hline No & 1516 & 20.0 \\
\hline Yes & 6066 & 80.0 \\
\hline
\end{tabular}

CEA, carcinoembryonic antigen; LND, dissected lymph nodes. 
Table 2

Univariate and multivariate analysis of prognostic factors associated with overall survival (Training set).

\begin{tabular}{|c|c|c|c|c|}
\hline \multirow[b]{2}{*}{ Variable } & \multicolumn{2}{|c|}{ Univariate analysis } & \multicolumn{2}{|c|}{ Multivariate analysis } \\
\hline & $\mathrm{HR}(95 \% \mathrm{Cl})$ & $P$ value & $\mathrm{HR}(95 \% \mathrm{Cl})$ & $P$ value \\
\hline \multicolumn{5}{|l|}{ Age } \\
\hline$\leq 65$ years & Reference & - & Reference & - \\
\hline$>65$ years & $1.89(1.63,2.19)$ & 0.000 & $2.25(1.82,2.78)$ & 0.000 \\
\hline \multicolumn{5}{|l|}{ Sex } \\
\hline Male & Reference & - & Reference & - \\
\hline Female & $0.73(0.63,0.85)$ & 0.000 & $0.65(0.52,0.82)$ & 0.000 \\
\hline \multicolumn{5}{|l|}{ Insurance } \\
\hline No & Reference & - & & \\
\hline Yes & $0.77(0.55,1.07)$ & 0.116 & & \\
\hline \multicolumn{5}{|l|}{ CEA } \\
\hline$\leq 5 \mathrm{ng} / \mathrm{mL}$ & Reference & - & Reference & - \\
\hline$>5 \mathrm{ng} / \mathrm{mL}$ & $1.65(1.38,1.97)$ & 0.000 & $1.40(1.13,1.74)$ & 0.002 \\
\hline \multicolumn{5}{|l|}{ T stage } \\
\hline T0/T1/T2 & Reference & - & Reference & - \\
\hline T3 & $1.61(1.17,2.22)$ & 0.004 & $1.80(1.05,3.09)$ & 0.032 \\
\hline T4 & $3.51(2.46,5.02)$ & 0.000 & $3.58(1.99,6.43)$ & 0.000 \\
\hline \multicolumn{5}{|l|}{ N stage } \\
\hline NO & Reference & - & Reference & - \\
\hline N1 & $1.25(1.06,1.48)$ & 0.008 & $1.16(0.89,1.51)$ & 0.266 \\
\hline N2 & $1.87(1.52,2.30)$ & 0.000 & $2.02(1.47,2.77)$ & 0.000 \\
\hline \multicolumn{5}{|c|}{ Tumor differentiation } \\
\hline Grade I/II & Reference & - & Reference & - \\
\hline Grade III/IV & $1.63(1.35,1.98)$ & 0.000 & $1.45(1.11,1.88)$ & 0.006 \\
\hline \multicolumn{5}{|l|}{ Tumor size } \\
\hline$\leq 3 \mathrm{~cm}$ & Reference & - & Reference & - \\
\hline
\end{tabular}




\begin{tabular}{|c|c|c|c|c|}
\hline \multirow[b]{2}{*}{$3-5 \mathrm{~cm}$} & \multicolumn{2}{|c|}{ Univariate analysis } & \multicolumn{2}{|c|}{ Multivariate analysis } \\
\hline & $1.10(0.89,1.35)$ & 0.375 & $0.90(0.68,1.18)$ & 0.451 \\
\hline$>5 \mathrm{~cm}$ & $1.53(1.25,1.86)$ & 0.000 & $1.29(0.98,1.69)$ & 0.066 \\
\hline \multicolumn{5}{|c|}{ Tumor deposits } \\
\hline Negative & Reference & - & Reference & - \\
\hline Positive & $1.99(1.66,2.39)$ & 0.000 & $1.30(0.98,1.71)$ & 0.066 \\
\hline \multicolumn{5}{|c|}{ Perineural invasion } \\
\hline Absent & Reference & - & Reference & - \\
\hline Present & $1.98(1.64,2.38)$ & 0.000 & $1.35(1.03,1.78)$ & 0.030 \\
\hline \multicolumn{5}{|c|}{ Number of LND } \\
\hline$<12$ & Reference & - & Reference & - \\
\hline$\geq 12$ & $0.79(0.68,0.93)$ & 0.004 & $0.68(0.54,0.85)$ & 0.001 \\
\hline \multicolumn{5}{|c|}{ Preoperative radiotherapy } \\
\hline No & Reference & - & Reference & - \\
\hline Yes & $0.86(0.72,1.02)$ & 0.081 & $1.00(0.77,1.28)$ & 0.972 \\
\hline
\end{tabular}


Table 3

Comparison of time-dependent AUC and C-index between the nomogram and the 8th AJCC staging system.

\begin{tabular}{|c|c|c|c|c|c|c|}
\hline & Training set & & & Validation set & & \\
\hline & Nomogram & 8th AJCC & $\begin{array}{l}\mathrm{P}- \\
\text { value }\end{array}$ & Nomogram & 8th AJCC & $\begin{array}{l}\mathrm{P} \text { - } \\
\text { value }\end{array}$ \\
\hline $\begin{array}{l}\text { 1-year } \\
\text { AUC } \\
(95 \% \mathrm{Cl})\end{array}$ & $0.71(0.65,0.77)$ & $0.57(0.50,0.64)$ & 0.000 & $0.74(0.66,0.81)$ & $0.58(0.49,0.66)$ & 0.000 \\
\hline $\begin{array}{l}\text { 3-year } \\
\text { AUC } \\
(95 \% \mathrm{Cl})\end{array}$ & $0.71(0.68,0.75)$ & $0.63(0.59,0.67)$ & 0.000 & $0.67(0.63,0.71)$ & $0.58(0.54,0.63)$ & 0.000 \\
\hline $\begin{array}{l}\text { 5-year } \\
\text { AUC } \\
(95 \% \mathrm{Cl})\end{array}$ & $0.69(0.64,0.73)$ & $0.61(0.56,0.65)$ & 0.001 & $0.68(0.63,0.73)$ & $0.61(0.56,0.66)$ & 0.040 \\
\hline $\begin{array}{l}\text { C-index } \\
(95 \% \mathrm{Cl})\end{array}$ & $0.70(0.67,0.72)$ & $0.63(0.60,0.67)$ & 0.000 & $0.67(0.63,0.71)$ & $0.61(0.56,0.66)$ & 0.005 \\
\hline
\end{tabular}


Table 4

Overall survival in rectal cancer associated with neoadjuvant radiotherapy among phase III RCTs

\begin{tabular}{|c|c|c|c|c|c|}
\hline study & $\begin{array}{l}\text { Treatment arm } \\
\text { (Sample size) }\end{array}$ & $\begin{array}{l}\text { Total dose/Daily } \\
\text { dose (Gy) }\end{array}$ & $\begin{array}{l}\text { Treatment interval } \\
\text { time (day) }\end{array}$ & $\begin{array}{l}5 \text {-year } \\
\text { OS (\%) }\end{array}$ & $\begin{array}{l}\mathrm{P} \text { - } \\
\text { value }\end{array}$ \\
\hline VASOG I & $R+S(189)$ & $20 / 2$ & 14 & $43.4 \%^{*}$ & 0.042 \\
\hline (1975) [42] & S (187) & & & $31.6 \%{ }^{*}$ & \\
\hline VASOG II & $R+S(126)$ & $31.5 / 1.75$ & immediate & $50.3 \%{ }^{*}$ & 0.997 \\
\hline (1986) [43] & S (136) & & & $49.6 \%^{*}$ & \\
\hline EORTC & $R+S(166)$ & $34.5 / 2.3$ & 11 & $69.1 \%^{*}$ & 0.08 \\
\hline (1988) [44] & $S(175)$ & & & $59.1 \%{ }^{*}$ & \\
\hline Stockholm I & $\mathrm{R}+\mathrm{S}(331)$ & $25 / 5$ & 7 & $42.0 \%{ }^{*}$ & NA \\
\hline (1990) [45] & S (348) & & & $41.9 \%^{*}$ & \\
\hline Goldberg & $R+S(146)$ & $15 / 5$ & 7 & $40.3 \%$ & 0.92 \\
\hline (1994) [46] & S (134) & & & $38.8 \%$ & \\
\hline Marsh & $R+S(143)$ & $20 / 5$ & 7 & $30.1 \%$ & 0.21 \\
\hline (1994) [47] & $S(141)$ & & & $30.5 \%$ & \\
\hline MRC II & R + S (139) & $40 / 2$ & 45 & $31 \%$ & 0.1 \\
\hline (1996) [48] & $S(140)$ & & & $38 \%$ & \\
\hline $\begin{array}{l}\text { Swedish rectal } \\
\text { cancer trial }\end{array}$ & $R+S(573)$ & $25 / 5$ & 7 & $58 \%$ & 0.004 \\
\hline (1997) [49] & S (574) & & & $48 \%$ & \\
\hline Dutch TME trial & R + TME (924) & $25 / 5$ & $<10(87 \%)$ & $62.2 \%$ & NA \\
\hline$(2001)[8,10]$ & TME (937) & & & $61.9 \%$ & \\
\hline \multicolumn{6}{|c|}{$\mathrm{R}$, radiotherapy; $\mathrm{S}$, surgery; TME, total mesorectal excision; $\mathrm{RCTs}$, randomized clinical trials } \\
\hline
\end{tabular}

\section{Figures}




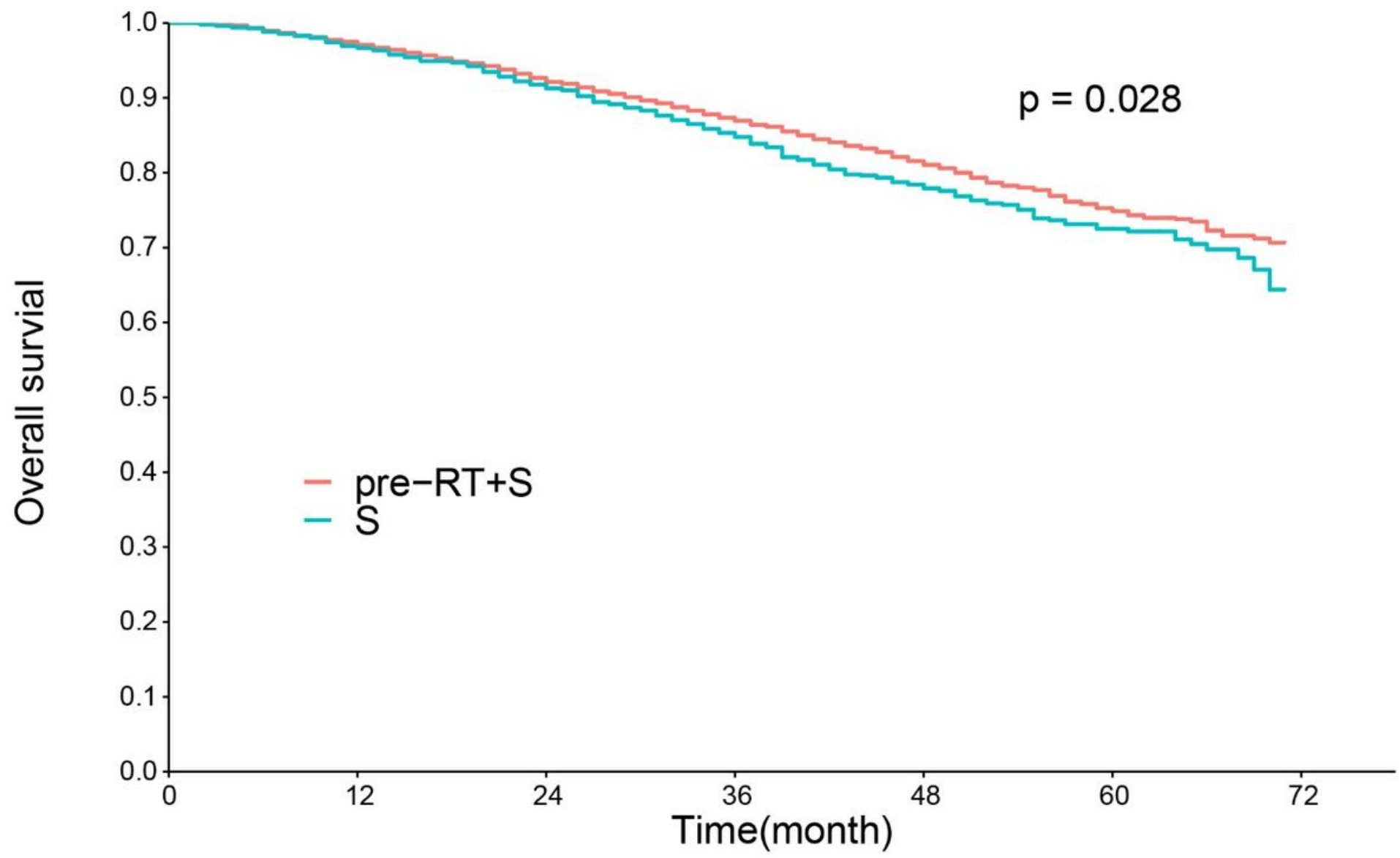

\begin{tabular}{|c|c|c|c|c|c|c|c|}
\hline & Numb & risk & & & & & \\
\hline pre-RT+S & 6066 & 5772 & 4257 & 2861 & 1736 & 756 & 0 \\
\hline S & 1516 & 1442 & 1092 & 771 & 471 & 219 & 0 \\
\hline & 0 & 12 & 24 & $\begin{array}{c}36 \\
\text { Time }\end{array}$ & 48 & 60 & 72 \\
\hline
\end{tabular}

\section{Figure 1}

Kaplan-Meier analysis of overall survival according to preoperative radiotherapy (pre-RT). S, surgery without pre-RT. 


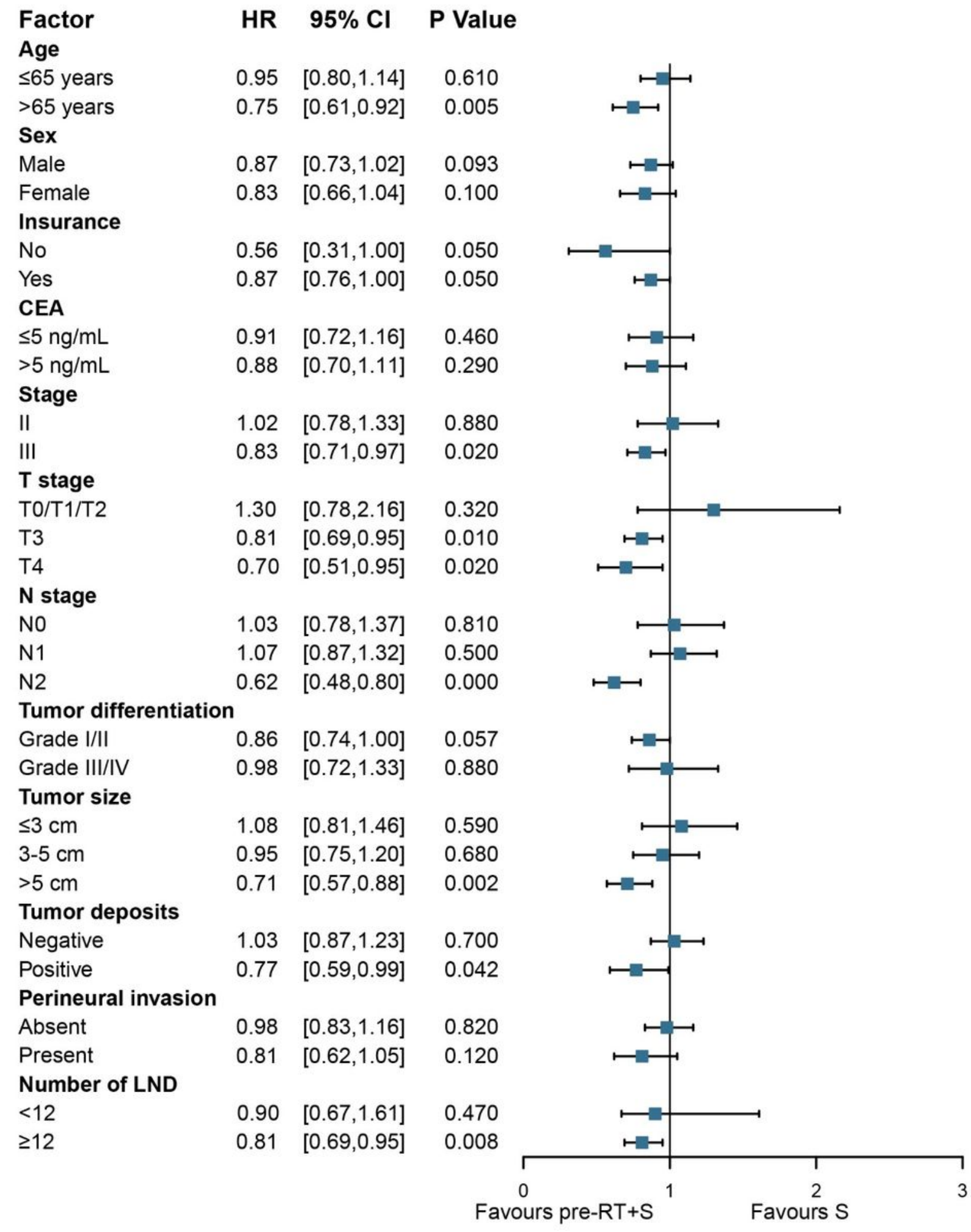

Figure 2

Subgroup analysis of OS stratified by risk factor. CEA, carcinoembryonic antigen; LND, dissected lymph nodes; pre-RT, preoperative radiotherapy; $\mathrm{S}$, surgery without pre-RT; HR, hazard ratio; $\mathrm{Cl}$, confidence interval. 
Points

$0 \quad 10$

0

Age

Sex

CEA

T stage

$\mathrm{N}$ stage

Tumor differentiation

Perineural invasion

Number of LND

$$
\leq 65 \text { years }
$$

$>65$ years

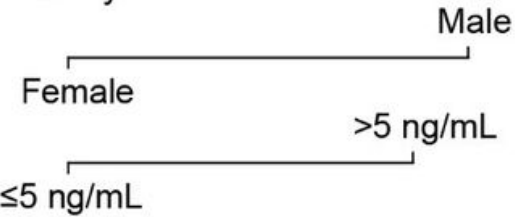

$\leq 5 \mathrm{ng} / \mathrm{mL}$

T3
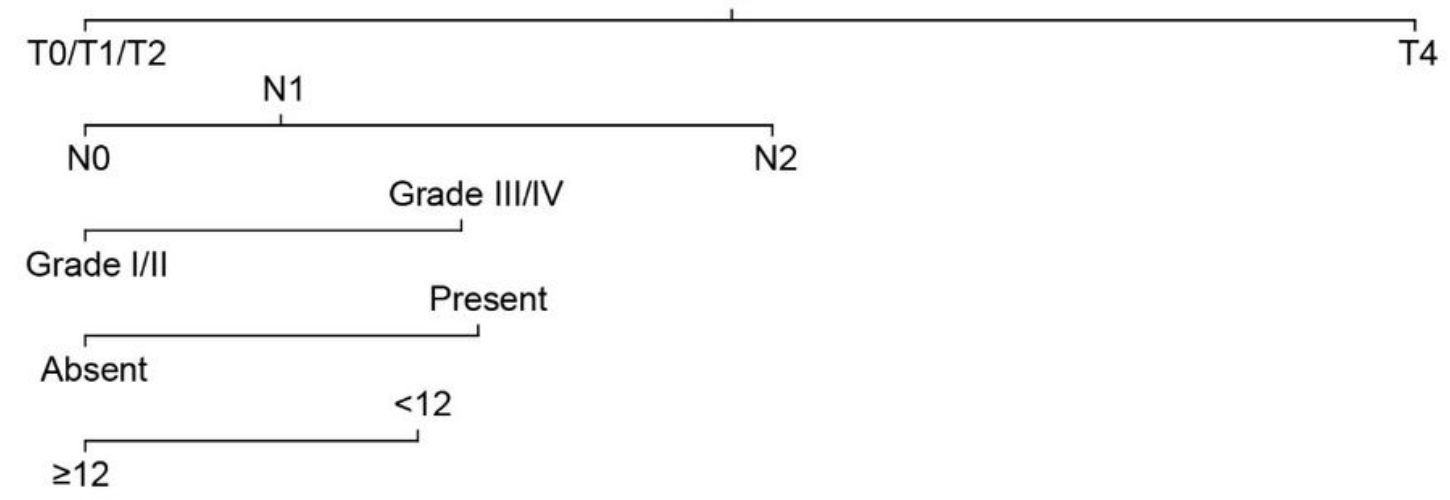

Total Points

\begin{tabular}{llllllll}
\hline & 50 & 100 & 150 & 200 & 250 & 300 & 350
\end{tabular}

1-year OS

$\begin{array}{lllll}0.95 & 0.9 & 0.85 & 0.8 & 0.75\end{array}$

3-year OS

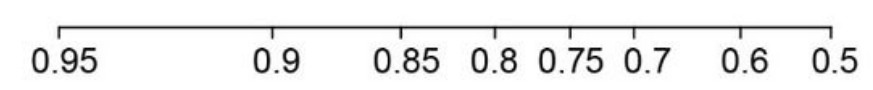

5-year OS

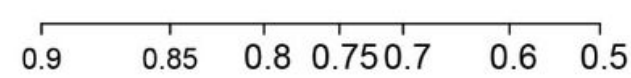

\section{Figure 3}

Locally advanced rectal cancer survival nomogram. (To use the nomogram, an individual patient's value is located on each variable axis, and a line is drawn upward to determine the number of points received for each variable value. The sum of these numbers is located on the Total Points axis, and a line is drawn downward to the OS axes to determine the likelihood of 1-, 3- or 5-year OS). OS, overall survival; CEA, carcinoembryonic antigen; LND, dissected lymph nodes. 
A

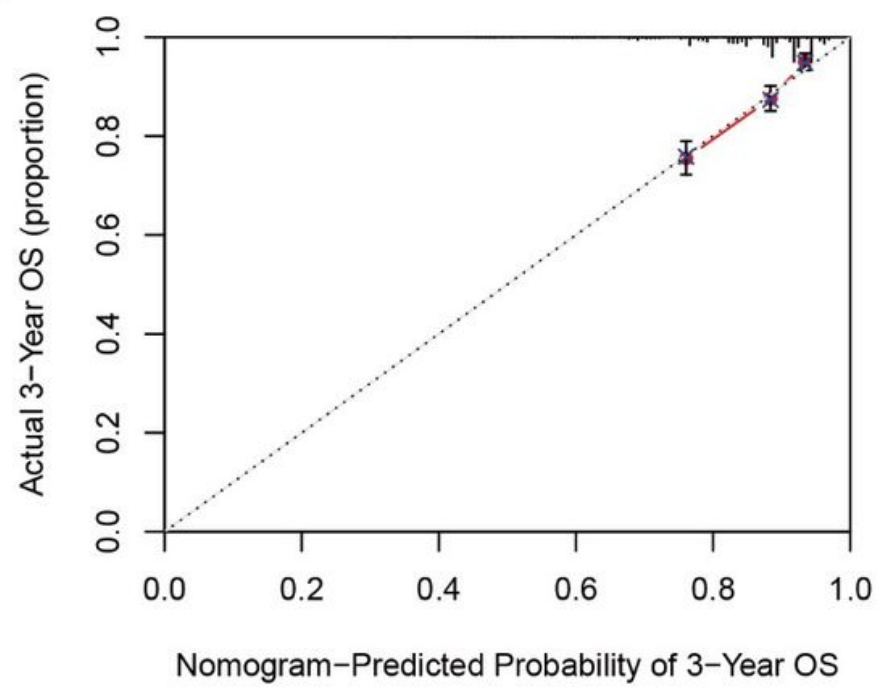

C

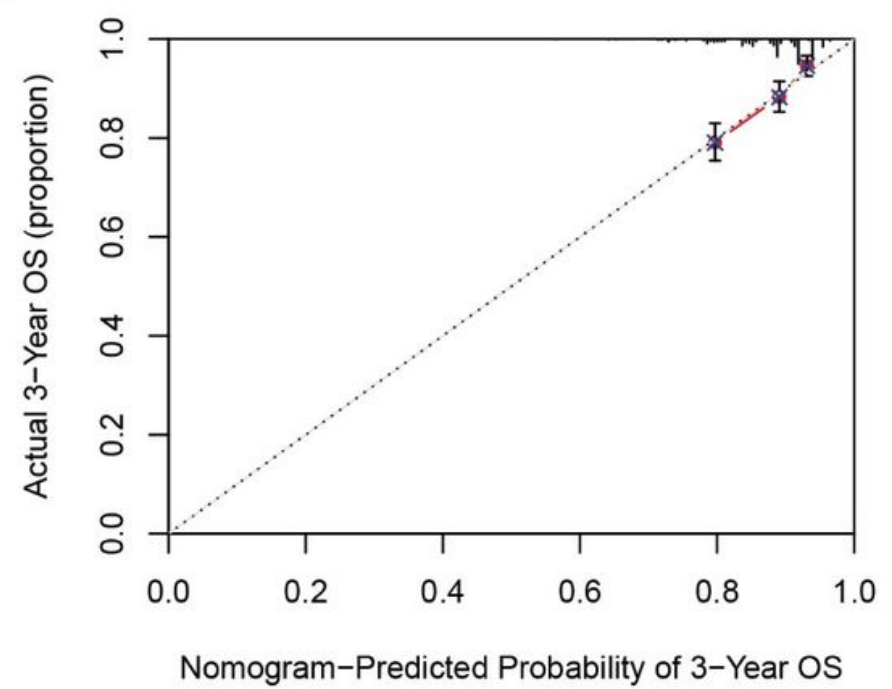

B

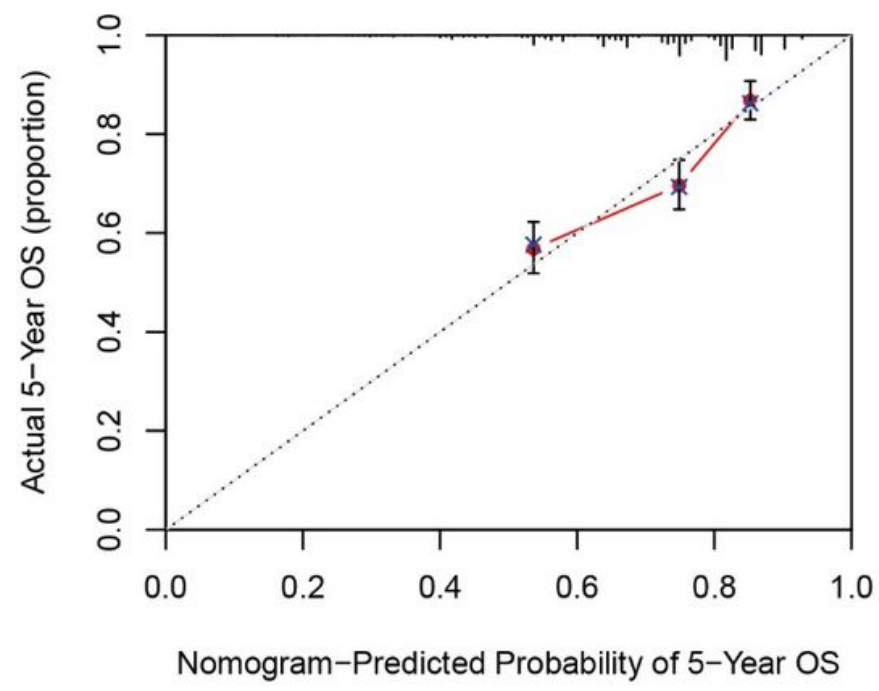

D

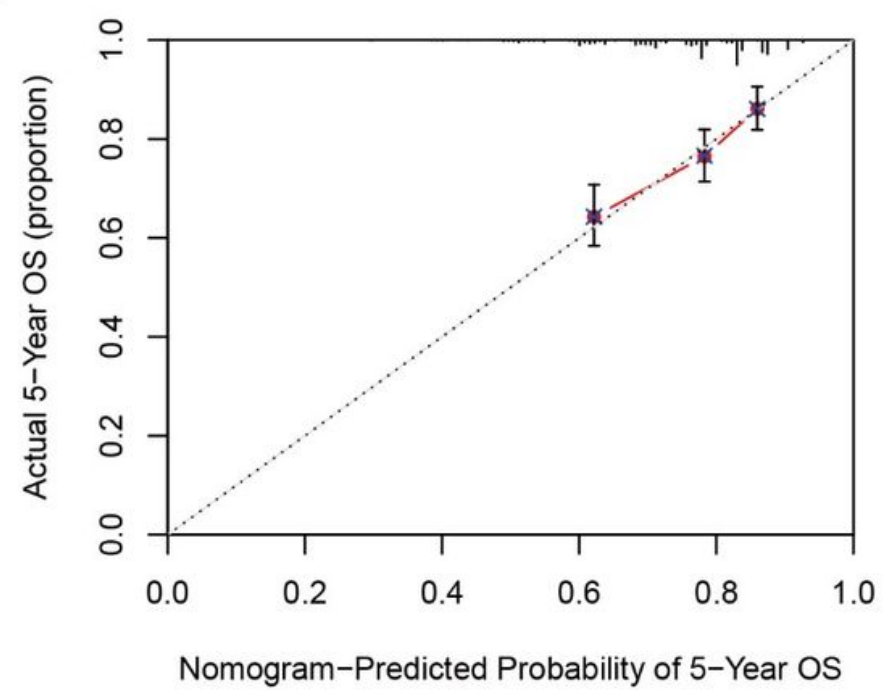

Figure 4

Calibrations of the nomogram for predicting survival rates. (A) 3-year, (B) 5-year in the training set and (C) 3-year, (D) 5-year in the validation set. Nomogram predicted probability of OS is plotted on the x-axis; actual overall survival is plotted on the $y$-axis. 
A

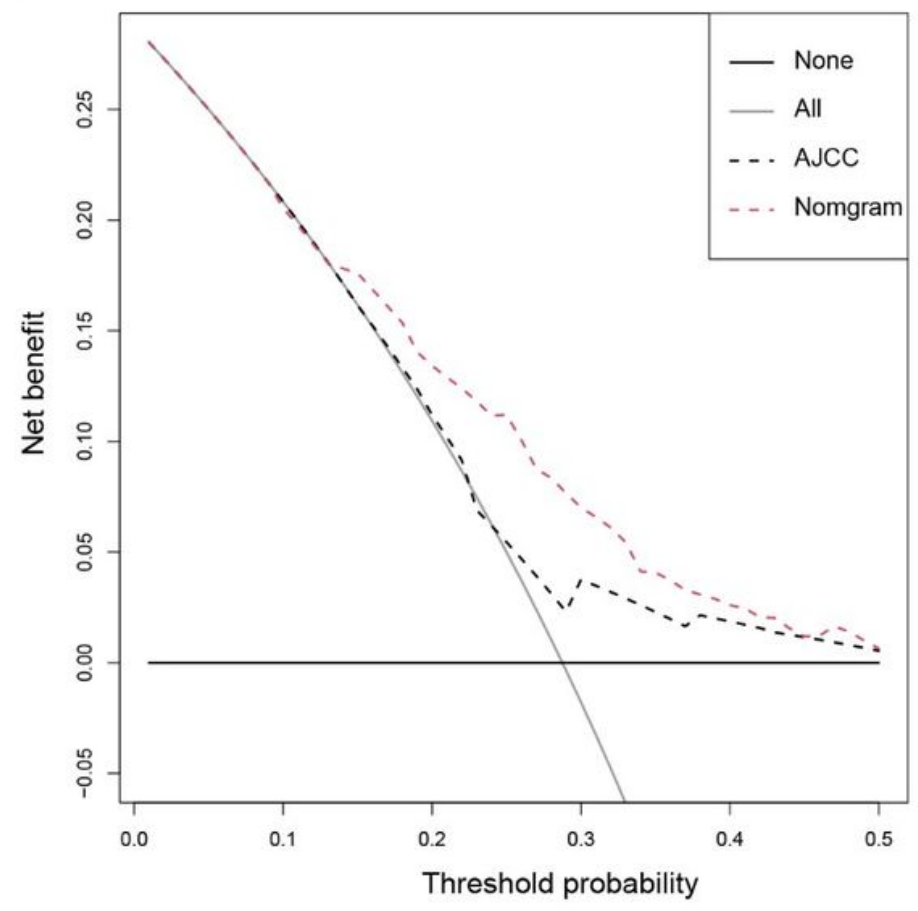

B

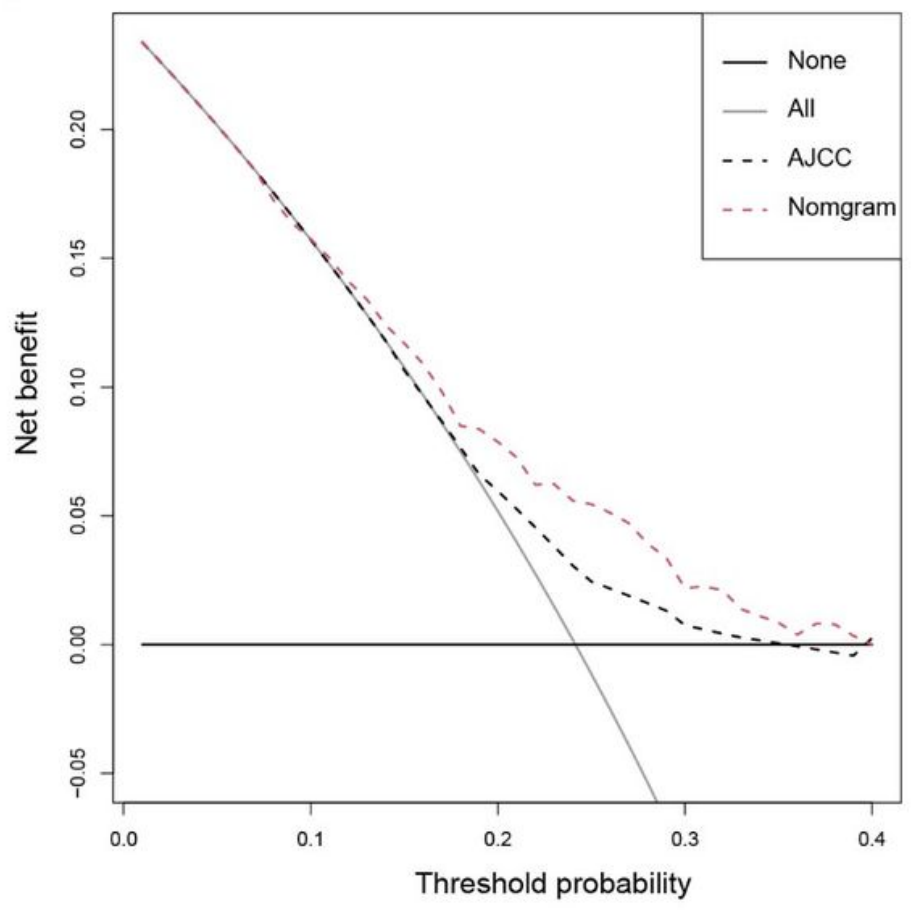

\section{Figure 5}

Decision curve analysis (DCA) of overall survival using nomogram and the 8th AJCC staging system. (A) DCA of 5-year OS in the training set; (B) DCA of 5-year OS in the validation set. The x-axis represents the threshold probability. The $y$-axis measures the net benefit. The threshold probability is where the expected benefit of treatment balances the expected benefit of avoiding treatment. The nomogram resulted in a superior net benefit to the 8th AJCC staging system, with a wide range of threshold probabilities. 
A
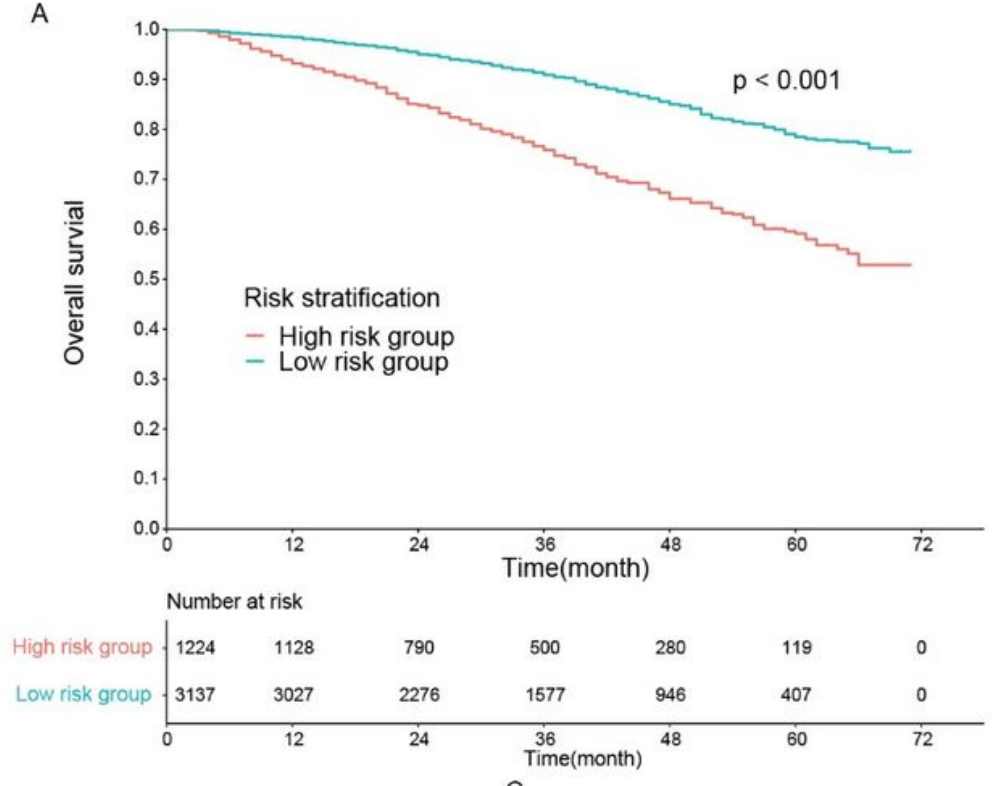

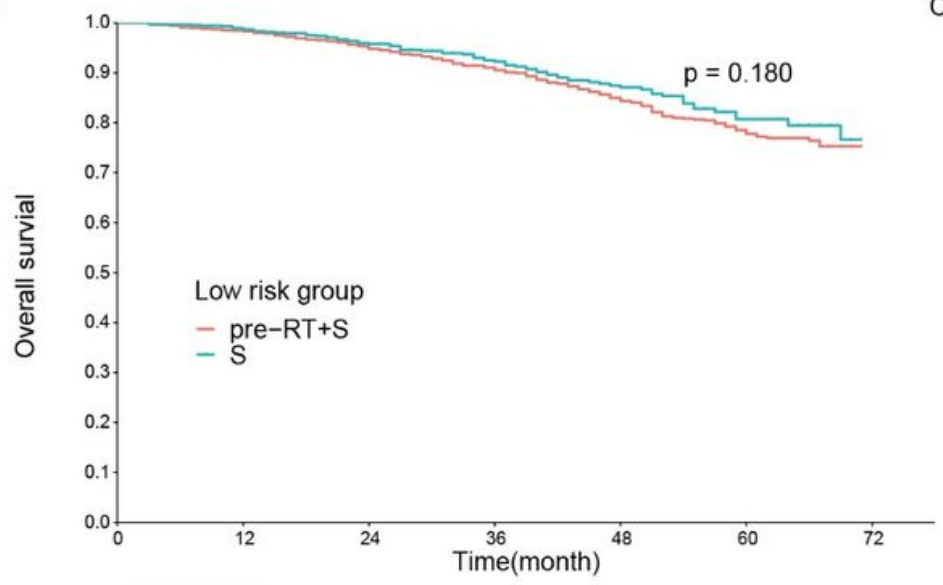

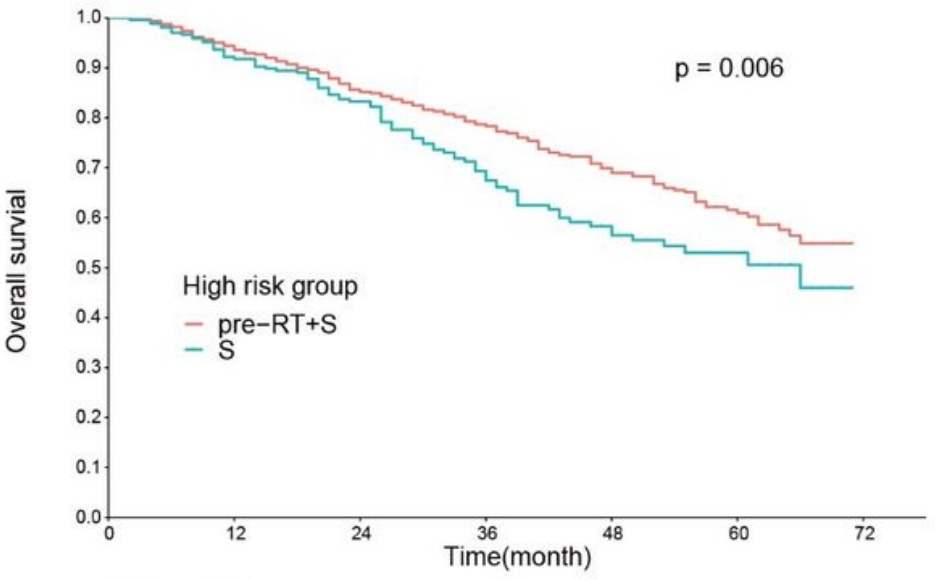

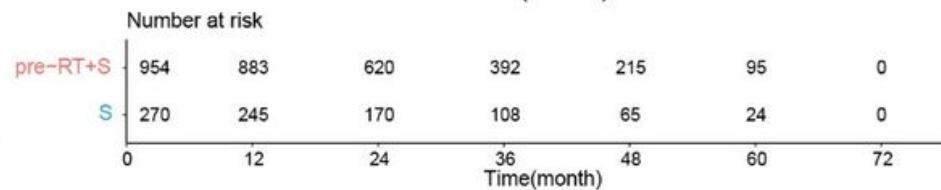

\section{Figure 6}

Kaplan-Meier analysis of overall survival according to (A) risk stratification (high risk group vs low risk group); (B) preoperative radiotherapy (pre-RT) for low-risk patients (pre-RT + S vs S) and (C) preoperative radiotherapy for high-risk patients (pre-RT+S vs $S$ ). S, surgery without pre-RT.

\section{Supplementary Files}

This is a list of supplementary files associated with this preprint. Click to download.

- FigureS1.tif

- TableS1.docx 